27(1), 159-168

\title{
News Impact Curves of Volatility for Asymmetric GARCH via LASSO
}

\author{
J.E. Yoon ${ }^{a} \cdot$ J.W. Lee ${ }^{a}$. S.Y. Hwang ${ }^{a, 1}$ \\ ${ }^{a}$ Department of Statistics, Sookmyung Women's University \\ (Received January 22, 2014; Revised February 4, 2014; Accepted February 6, 2014)
}

\begin{abstract}
The news impact curve(NIC) originally proposed by Engle and $\mathrm{Ng}$ (1993) is a graphical representation of volatility for financial time series. The NIC is a simple but a powerful tool for identifying variability of a given time series. It is noted that the NIC is suited to symmetric volatility. Recently a lot of attention has been paid to asymmetric volatility models and therefore asymmetric version of the NIC would be useful in the field of financial time series. In this article, we propose to incorporate LASSO in constructing asymmetric NICs based on asymmetric GARCH models. In particular, bilinear GARCH models are considered and illustrated via KOSDAQ data.
\end{abstract}

Keywords: Bilinear GARCH, Lasso, Two dimensional NIC.

\section{1. 서론}

금융시계열의 변동성(volatility, 조건부 분산, 일반적으로 $h_{t}$ 로 표현함)은 과거시점의 수익률에 영향을 받으며 과거 시점의 수익률에 따라 특정 시점에서의 변동성이 달라진다. Engle과 Ng (1993)가 제안한 News Impact Curve(NIC)는 한 시점 전에서의 수익률이 현 시점의 변동성에 얼마나 영향을 주는지 측 정할 수 있도록 $t-1$ 시점의 수익률과 $t$ 시점에서의 변동성 $h_{t}$ 간의 관계를 그래프로 표현한 것이다. 이 때 $t-2$ 이전 시점까지의 정보는 상수로 간주하여 고정시킨다. 최근에 Lee 등 (2013)은 한 시점 전 의 수익률 뿐 아니라 $t-2$ 시점의 수익률을 새로운 축으로 추가한 2 차원 $\mathrm{NIC}$ (two dimensional NIC; $2 \mathrm{D}-\mathrm{NIC}$ )와 $t-1$ 시점에서부터 $t-5$ 시점까지의 수익률의 선형결합으로 만든 새로운 주성분(principal component) 인공축을 이용한 $\mathrm{NIC}(\mathrm{PCA}$ in $\mathrm{NIC})$ 를 제안하였다.

논문에서는 전통적인 $\mathrm{NIC}$ 를 비대칭성 및 LASSO(Least Absolute Shrinkage and Selection Operator regression)를 이용하여 개선시키는 방안에 대해 연구하고 있다. 한 달간의 수익률, $t-1$ 시점에서부 터 $t-22$ 시점까지의 수익률을 차원축소한 수익률과 비대칭 변동성의 관계를 그래프로 나타낸 LASSO $\mathrm{NIC}$ 와 LASSO 2 차원 $\mathrm{NIC}$ 를 소개하고자 한다. 빅 데이터 분석 기법 중 하나인 LASSO는 선형 모형에 서 변수 선택 방법의 하나로 다차원의 변수들 중 일부 변수를 0 으로 수축시킴으로서 차원을 축소하는 방 법이다. 이를 통해 일부 두 시점 혹은 다섯 시점의 수익률만을 고려했던 것에서 훨씬 이전 시점의 수익 률까지 고려할 수 있게 되었고, 과거 한 달 동안의 수익률과 변동성과의 관계가 어떻게 나타나는지 그 래프를 통해 나타내었다는 점에서 실용적인 방법이라 생각된다. 제안한 방법을 국내 금융시계열 자료인 $\mathrm{KOSDAQ}$ 에 적용해보았다.

\footnotetext{
${ }^{1}$ Corresponding author: Professor, Department of Statistics, Sookmyung Women's University, Yongsan-Gu, Seoul 142-742, Korea. E-mail: shwang@sookmyung.ac.kr
} 


\section{2. 비대칭 GARCH와 LASSO}

금융시계열의 변동성은 일반적인 시계열에서는 잘 나타나지 않는 급첨(leptokurtic)성질, 변동성 집 중(volatility clustering)현상, 비대칭성 현상 등과 같은 성질들을 보이는 경향이 있다. 이러한 금융시 계열 변동성의 특징을 반영하는 모형으로 Engle (1982)은 AutoRegressive Conditional Heteroscedas$\mathrm{tic}$ (간략히 $\mathrm{ARCH}$ )모형을 제안하였으며 Bollerslev (1986)는 $\mathrm{ARCH}$ 모형을 확장한 모형으로 다음과 같 은 $\operatorname{GARCH}(p, q)$ 모형을 제안하였다.

$$
\begin{aligned}
\epsilon_{t} & =\sqrt{h_{t}} e_{t}, \\
h_{t} & =\alpha_{0}+\sum_{i=1}^{p} \alpha_{i} \epsilon_{t-i}^{2}+\sum_{j=1}^{q} \beta_{j} h_{t-j},
\end{aligned}
$$

여기서 $\epsilon_{t}$ 는 평균 0 인 중심화 수익률(centered log-return)을 나타낸다. 위와 같은 GARCH모형에서는 과거의 수익률이 제곱형태로 반영되므로 현재의 조건부 분산은 과거 수익률들의 크기에만 영향을 받고 부호에 따른 효과는 반영되지 않는다. 따라서 과거의 수익률과 현재의 변동성 사이의 비대칭적 관계를 반영하기 어렵다는 문제가 있다. 이러한 단점을 보완하기 위해 과거의 수익률들과 변동성의 비대칭성을 강조하는 T-GARCH(Threshold $\mathrm{GARCH}$ )모형과 $\mathrm{BL}-\mathrm{GARCH}(\mathrm{Bilinear} \mathrm{GARCH}$ )모형이 제안되었다.

\subsection{T-GARCH $(1,1)$}

분계점을 가진 비대칭 변동성 모형으로서 Rabemananjara와 Zakoian (1993)이 제안한 threshlod$\mathrm{GARCH}$ 모형은 다음과 같다.

$$
\begin{aligned}
\epsilon_{t} & =\sqrt{h_{t}} e_{t}, \\
h_{t} & =\alpha_{0}+\sum_{i=1}^{p}\left[\alpha_{i 1}\left(\epsilon_{t-i}^{+}\right)^{2}+\alpha_{i 2}\left(\epsilon_{t-i}^{-}\right)^{2}\right]+\sum_{j=1}^{q} \beta_{j} h_{t-j},
\end{aligned}
$$

여기서 $\alpha_{i 1} \geq 0, \alpha_{i 2} \geq 0, \epsilon^{+}=\max (\epsilon, 0), \epsilon^{-}=\max (-\epsilon, 0)$ 이다. 위의 모형에서 모수 $\alpha_{i 1}$ 과 모수 $\alpha_{i 2}$ 가 서로 다른 값을 가짐으로 비대칭성을 나타낼 수 있다. 일차모형인 T-GARCH(1,1)모형은 다음과 같다.

$$
\begin{aligned}
\epsilon_{t} & =\sqrt{h_{t}} e_{t}, \\
h_{t} & =\alpha_{0}+\alpha_{11}\left(\epsilon_{t-1}^{+}\right)^{2}+\alpha_{12}\left(\epsilon_{t-1}^{-}\right)^{2}+\beta_{1} h_{t-1} .
\end{aligned}
$$

이 모형은 좋은 정보 $\left(\epsilon^{+}\right)$와 나쁜 정보 $\left(\epsilon^{-}\right)$에 따라 각각 다르게 반영함으로써 변동성의 비대칭성을 반영 할 수 있고 지렛대 효과(leverage effect)를 효과적으로 설명할 수 있다. 여기서 만일 $\alpha_{11}=\alpha_{12}$ 라면, $\mathrm{T}-\mathrm{GARCH}(1,1)$ 모형은 $\operatorname{GARCH}(1,1)$ 모형과 같아진다.

\section{2. $\operatorname{BL}-\operatorname{GARCH}(1,1)$}

Storti와 Vitale (2003)은 이전 시점의 변동성과 수익률의 교차항을 추가한 다음과 같은 BL-GARCH모 형을 제시하였다.

$$
\begin{aligned}
& \epsilon_{t}=\sqrt{h_{t}} e_{t} \\
& h_{t}=\alpha_{0}+\sum_{i=1}^{p} \alpha_{i} \epsilon_{t-i}^{2}+\sum_{j=1}^{q} \beta_{j} h_{t-j}+\sum_{k=1}^{r} \gamma_{k} \epsilon_{t-k} \sqrt{h_{t-k}},
\end{aligned}
$$


여기서 $r=\min \{p, q\}$ 이며, $\gamma_{k}=0$ 이면 $\mathrm{GARCH}$ 모형과 같아진다. 일차모형인 $\operatorname{BL}-\mathrm{GARCH}(1,1)$ 모형 은 다음과 같다.

$$
\begin{aligned}
\epsilon_{t} & =\sqrt{h_{t}} e_{t}, \\
h_{t} & =\alpha_{0}+\alpha_{1} \epsilon_{t-1}^{2}+\beta_{1} h_{t-1}+\gamma_{1} \epsilon_{t-1} \sqrt{h_{t-1}},
\end{aligned}
$$

여기서 $\alpha_{0}>0, \alpha_{1}>0, \beta_{1}>0, \gamma_{1}^{2}<4 \alpha_{1} \beta_{1}$ 은 변동성이 양수이기 위해 필요한 조건이다. $\mathrm{BL}-\mathrm{GARCH}$ 모형에서는 추가된 변동성과 수익률의 곱으로 이루어진 항 $\epsilon_{t-k} \sqrt{h_{t-k}}$ 으로 지렛대 효 과(leverage effect)를 설명할 수 있다. 즉, $\gamma_{k}$ 가 음수일 경우 $\epsilon_{t-k}$ 이 양수일 때는 변동성 $h_{t}$ 가 감소하지 만 $\epsilon_{t-k}$ 이 음수일 때는 변동성 $h_{t}$ 가 증가하게 되어 비대칭적 변동성을 반영할 수 있게 되는 것이다.

$\mathrm{BL}-\mathrm{GARCH}(1,1)$ 모형에서 $t$ 시점에서의 변동성과 $t-1$ 시점에서의 수익률 간의 관계를 보기 위해 $t-$ 2 시점 이하의 수익률들과 변동성들은 모두 상수로 변환한 후에 표현한 NIC 방정식은 다음과 같이 유도 할 수 있다.

$$
\begin{aligned}
h_{t} & =\alpha_{0}+\alpha_{1} \epsilon_{t-1}^{2}+\beta_{1} h_{t-1}+\gamma_{1} \epsilon_{t-1} \sqrt{h_{t-1}} \\
& =\alpha_{0}+\alpha_{1} \epsilon_{t-1}^{2}+\gamma_{1} \sqrt{\frac{\alpha_{0}}{1-\alpha_{1}-\beta_{1}}} \epsilon_{t-1}+\frac{\alpha_{0} \beta_{1}}{1-\alpha_{1}-\beta_{1}},
\end{aligned}
$$

여기서 $E h_{t-1}=\alpha_{0} /\left(1-\alpha_{1}-\beta_{1}\right)$ 을 이용하였다 (cf. Choi 등, 2012). 기존의 NIC에 $t-2$ 시점의 수 익률을 추가함으로써 3 차원 좌표축으로 확장한 2 차원 $\mathrm{NIC}$ 방정식은 다음과 같은 복잡한 공식으로 정리 된다.

$$
\begin{aligned}
h_{t}= & \alpha_{0}+\alpha_{1} \epsilon_{t-1}^{2}+\beta_{1} h_{t-1}+\gamma_{1} \epsilon_{t-1} \sqrt{h_{t-1}} \\
= & \alpha_{0}+\alpha_{1} \epsilon_{t-1}^{2}+\beta_{1}\left[\alpha_{0}+\alpha_{1} \epsilon_{t-2}^{2}+\beta_{1} h_{t-2}+\gamma_{1} \epsilon_{t-2} \sqrt{h_{t-2}}\right] \\
& +\gamma_{1} \epsilon_{t-1} \sqrt{\alpha_{0}+\alpha_{1} \epsilon_{t-2}^{2}+\beta_{1} h_{t-2}+\gamma_{1} \epsilon_{t-2} \sqrt{h_{t-2}}} \\
= & \alpha_{0}\left(1+\beta_{1}\right)+\alpha_{1} \epsilon_{t-1}^{2}+\gamma_{1} \epsilon_{t-1} \sqrt{\alpha_{0}+\alpha_{1} \epsilon_{t-2}^{2}+\beta_{1} h_{t-2}+\gamma_{1} \epsilon_{t-2} \sqrt{h_{t-2}}} \\
& +\alpha_{1} \beta_{1} \epsilon_{t-2}^{2}+\beta_{1} \gamma_{1} \epsilon_{t-2} \sqrt{h_{t-2}}+\beta_{1}^{2} h_{t-2} \\
= & \alpha_{0}\left(1+\beta_{1}\right)+\alpha_{1} \epsilon_{t-1}^{2}+\gamma_{1} \epsilon_{t-1} \sqrt{\alpha_{0}+\alpha_{1} \epsilon_{t-2}^{2}+\frac{\alpha_{0} \beta_{1}}{1-\alpha_{1}-\beta_{1}}+\gamma_{1} \epsilon_{t-2} \sqrt{\frac{\alpha_{0}}{1-\alpha_{1}-\beta_{1}}}} \\
& +\alpha_{1} \beta_{1} \epsilon_{t-2}^{2}+\beta_{1} \gamma_{1} \epsilon_{t-2} \sqrt{\frac{\alpha_{0}}{1-\alpha_{1}-\beta_{1}}}+\frac{\alpha_{0} \beta_{1}^{2}}{1-\alpha_{1}-\beta_{1}},
\end{aligned}
$$

여기서 $E h_{t-2}=\alpha_{0} /\left(1-\alpha_{1}-\beta_{1}\right)$ 을 이용하였다. $\operatorname{GARCH}(1,1)$ 모형과 $\operatorname{T-GARCH}(1,1)$ 모형에서의 $\mathrm{NIC}$ 방정식은 Lee 등 (2013)을 참고하기 바란다.

\subsection{LASSO}

Tibshirani $(1996 \mathrm{a}, 1996 \mathrm{~b})$ 가 제안한 LASSO는 일반적으로 많이 사용하는 최소제곱추정법(OLS)의 문 제점들을 보완하기 위하여 제안된 부분 선택법(subset selection)과 릿지 회귀분석(ridge regression)을 동시에 실시함으로써 부분 선택법과 릿지 회귀분석의 장점을 반영한 모수 추정법이라 할 수 있다.

표준화된 설명변수 $x_{i j}$ 들과 반응변수 $y_{i}$ 가 있을 때 $\mathrm{LASSO}$ 는 다음의 식을 최소화하는 $\beta$ 값을 추정한다.

$$
\sum_{i=1}^{N}\left(y_{i}-\sum_{j=1}^{p} x_{i j} \beta_{j}\right)^{2}+\lambda \sum_{j=1}^{p}\left|\beta_{j}\right|,
$$


여기서 $\lambda$ 는 튜닝 모수(tuning parameter)라 하며, $\sum\left|\beta_{j}\right| \leq s$ 라는 제한조건 아래 제곱합을 최소로 만들어주는 모수를 추정하는 방법이다. $\hat{\beta}_{j}^{0}$ 를 최소제곱추정량으로 구한 모수 값이라 했을 때, $t_{0}=$ $\sum\left|\hat{\beta_{j}^{0}}\right|$ 으로 놓을 수 있으며 이때 튜닝 모수 $\lambda$ 값이 $t_{0}$ 값보다 작을 경우에 수축(shrinkage) 현상이 일 어나면서 몇몇의 계수들은 0 의 값을 갖게 되는 것이다.

$\mathrm{LASSO}$ 는 서로 상관성이 높은 변수들 사이에서는 대표 변수 하나만 추출하는 성질을 가지고 있으며 이 로 인해 중요한 변수라 생각되는 변수가 다른 변수와 중복되어 추출되지 않는 경우가 발생할 수 있다. 따라서 변수를 추출하여 차원을 축소하는 과정에서 변수들 사이의 공분산을 고려하여 진행하여야 한다. 자세한 내용은 Park 등 (2011)을 참고하기 바란다.

\section{LASSO를 통한 NIC}

한 달간의 수익률, $t-1$ 시점에서부터 $t-22$ 시점까지의 22 개의 수익률들에 대해 LASSO를 이용하여 차 원을 축소한 후 변동성과의 관계를 그래프로 나타낸 LASSO NIC와 LASSO 2 차원 $\mathrm{NIC}$ 를 소개하고자 한다.

\subsection{LASSO NIC}

Engle과 $\mathrm{Ng}$ (1993)이 소개한 NIC는 $t-2$ 시점 이하의 수익률은 모두 상수로 변환한 후 $t-1$ 시점에서 의 수익률과 $t$ 시점에서의 변동성과의 관계를 그래프로 그린 것이다. 이 그래프에서는 2 차원 좌표평면에 수익률 $\epsilon_{t-1}$ 은 가로축에, 변동성 $h_{t}$ 는 세로축에 나타내며, 이는 금융시계열 자료가 가지고 있는 특성인 지렛대 효과를 확인하는데 적합하다.

본 절에서는 한 달 동안의 수익률, 즉 $t-1$ 시점부터 $t-22$ 시점까지의 수익률을 고려한 LASSO NIC를 제안한다. 총 22 개의 수익률을 모두 고려하는 이 LASSO NIC는 $t-1$ 시점부터 $t-22$ 시점까지의 수 익률들을 변수로 하여 $\mathrm{LASSO}$ 를 통해 추정된 식에서 가장 영향력이 큰 시차의 수익률을 가로축으로, $\mathrm{LASSO}$ 를 통해 추정된 변동성 $\left(\hat{h_{t}^{L}}\right)$ 을 세로축으로 한 후 $\mathrm{LASSO}$ 추정식으로 추정된 점들을 좌표 평면 상에 나타낸 것이다. $\operatorname{GARCH}(1,1)$ 모형과 T-GARCH$(1,1)$ 모형에서 각각 아래의 식을 이용하여 수익 률들을 상수화 하였다 ( $c f$. Choi 등, 2012).

$$
\begin{aligned}
& E\left(\epsilon_{t-k}^{2}\right)=\frac{\alpha_{0}}{1-\alpha_{1}-\beta_{1}}, \\
& E\left(\epsilon_{t-k}^{+2}\right)=E\left(\epsilon_{t-k}^{-2}\right)=\frac{1}{2} \cdot \frac{\alpha_{0}}{1-\frac{1}{2}\left(\alpha_{11}+\alpha_{12}\right)-\beta_{1}} .
\end{aligned}
$$

\subsection{LASSO 2차원 NIC}

2 차원 $\mathrm{NIC}$ 는 기존의 $\mathrm{NIC}$ 에 $t-2$ 시점의 수익률을 추가함으로써 3 차원 좌표축으로 확장한 것이었다. 3 차원으로 확장함으로써 $t$ 시점에서의 변동성과 $t-1$ 시점과 $t-2$ 시점에서의 수익률 간의 관계를 시각 적으로 쉅게 볼 수 있었다. 또한 2 차원 $\mathrm{NIC}$ 는 한 시점 전과 두 시점 전까지의 수익률을 모두 고려하여 변동성을 나타내므로 기존의 NIC보다 예측의 신뢰도가 올라간다고 볼 수 있었다 ( $c f$. Lee 등, 2013).

앞에서 제안한 LASSO NIC를 위와 같은 방법으로 3 차원으로 확장하여 LASSO 2 차원 NIC를 만들었 다. $\mathrm{LASSO}$ 를 통해 추정된 식에서 가장 영향력이 높은 두 시점의 수익률을 각각의 축으로 하여 3 차원 좌표축으로 확장한 것이다. LASSO NIC와 달리 LASSO 2 차원 $\mathrm{NIC}$ 는 가장 영향력이 큰 변수와 다음 으로 영향력이 큰 변수를 동시에 고려하여 두 변수가 $t$ 시점에서의 변동성에 어떻게 영향을 주는지 확인 할 수 있다는 장점이 있다. 


\section{4. 국내 금융시계열에의 응용: KOSDAQ}

본 절에서는 국내 금융시계열 자료인 $\operatorname{KOSDAQ}$ 에 $\operatorname{GARCH}(1,1)$ 모형과 $\mathrm{T}-\mathrm{GARCH}(1,1)$ 모형, $\mathrm{BL}-$ $\mathrm{GARCH}(1,1)$ 모형을 적합 시켜 보았다. 그 후 각각 LASSO $\mathrm{NIC}$ 와 LASSO 2 차원 $\mathrm{NIC}$ 를 적용시켜 그래프를 그려 보았다. 2010년 3월 2일부터 2013년 3월 2일까지, 총 749개의 KOSDAQ자료의 수익률 을 로그 차분 후 백분율로 변형하여 이용하였으며 수익률이 과거 수익률에 조건부적으로 정규분포를 따 른다고 가정하였다.

\section{1. 모형 1: GARCH(1,1)-LASSO NIC와 LASSO 2차원 NIC}

변동성에 영향을 끼치는 시차가 한 달 동안의 수익률이라 가정하고, $t-1$ 시점부터 $t-22$ 시점까지의 22 개의 수익률들을 설명변수로 하여 LASSO를 실시한 결과는 다음과 같다.

$$
\begin{aligned}
h_{t}= & 0.409765+0.248385 \epsilon_{t-2}^{2}+0.173659 \epsilon_{t-3}^{2}+0.120733 \epsilon_{t-4}^{2}+0.083519 \epsilon_{t-5}^{2} \\
& +0.057626 \epsilon_{t-6}^{2}+0.039939 \epsilon_{t-7}^{2}+0.027338 \epsilon_{t-8}^{2}+0.018475 \epsilon_{t-9}^{2}+0.012727 \epsilon_{t-10}^{2} \\
& +0.008247 \epsilon_{t-11}^{2}+0.004995 \epsilon_{t-12}^{2}+0.003010 \epsilon_{t-13}^{2}+0.001615 \epsilon_{t-14}^{2},
\end{aligned}
$$

여기서 반응변수 $h_{t}$ 는 모형 (즉, $\operatorname{GARCH}(1,1)$ )을 통하여 적합(추정)된 변동성을 의미한다. 위의 식을 보면 고려한 22 개의 수익률 중에서 13 개의 수익률만 시점 $t$ 에서의 변동성에 영향을 주고 있고, 나머지 9 개의 수익률 변수는 0 으로 수축되어 모형에서 제외되었음을 알 수 있다. 일반적으로는 시점 $t$ 에서 가 장 가까운 바로 전 시점, $t-1$ 에서의 수익률이 가장 영향력이 클 것이라고 생각하기 쉬우나 위의 결과를 보면 $t-1$ 시점에서의 수익률은 모형에 포함되어 있지 않다. 이는 서로 상관성이 높은 변수들 사이에서 는 대표 변수 하나만 추출하는 $\mathrm{LASSO}$ 의 특성상 $t-2$ 시점에서의 수익률과 $t-1$ 시점에서의 수익률 간 의 상관계수가 0.5 로 두 변수 간 상관성이 높으므로 $t-1$ 시점에서의 수익률이 생략이 된 것이라 생각된 다.

$\mathrm{LASSO}$ 결과 나온 가장 영향력 있는 $t-2$ 시점의 수익률과 변동성과의 관계를 보기 위해 $t-2$ 시점의 수 익률 $\epsilon_{t-2}^{2}$ 를 제외하고 나머지 수익률 변수들은 상수화한 결과는 다음과 같다.

$$
h_{t}=0.248385 \epsilon_{t-2}^{2}+1.577303 \text {. }
$$

Figure 4.1(a)는 위 식을 이용한 LASSO NIC이다. 0을 중심으로 대칭인 형태를 보이고 있으며 이는 $\operatorname{GARCH}(1,1)$ 모형의 특징인 대칭성을 보여주고 있음을 알 수 있다.

$\mathrm{LASSO} \mathrm{NIC}$ 에 대한 추정식에서 $t-2$ 시점의 수익률 다음으로 영향력이 큰 변수는 $t-3$ 시점의 수익률 이다. LASSO NIC에 $t-3$ 시점에서의 수익률까지 고려하여 LASSO 2 차원 $\mathrm{NIC}$ 를 만들어 보았다. 두 수익률, $\epsilon_{t-2}^{2}$ 과 $\epsilon_{t-3}^{2}$ 을 이용한 LASSO 2 차원 NIC는 다음과 같다.

$$
h_{t}=0.248385 \epsilon_{t-2}^{2}+0.173659 \epsilon_{t-3}^{2}+1.209918 \text {. }
$$

이 식을 이용한 LASSO 2차원 NIC는 Figure 4.1(b)와 같다. Figure 4.1(b)에서 $\left(\epsilon_{t-2}, \epsilon_{t-3}\right)=(0,0)$ 을 중심으로 모든 방향에서 대칭으로 증가하는 포물선 모양임을 알 수 있으며 이는 $t-2$ 시점이 일정하게 고정되어 있을 때 $t-3$ 시점에서의 수익률은 $t$ 시점에서의 변동성에 부호와 관계없이 동일한 영향을 준다 는 것을 의미한다. $t-3$ 시점이 고정되어 있을 때 $t-2$ 시점에서의 수익률과 $t$ 시점에서의 변동성의 관계 도 마찬가지이다. 


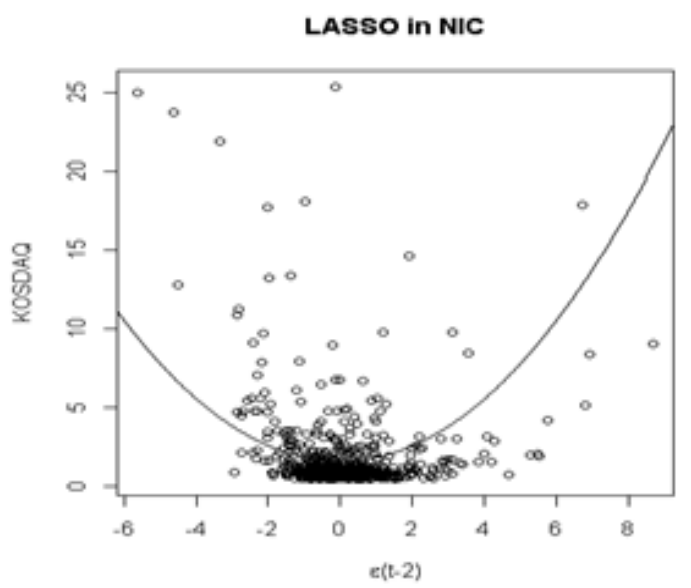

(a) LASSO NIC

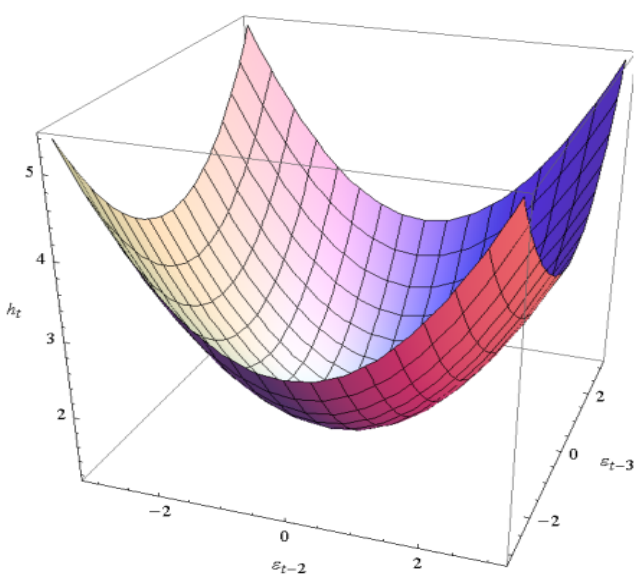

(b) LASSO 2차원 NIC

Figure 4.1. $\operatorname{GARCH}(1,1)$

\section{2. 모형 2: T-GARCH(1,1) - LASSO NIC와 LASSO 2차원 NIC}

749 개의 $\mathrm{KOSDAQ}$ 수익률 자료에 T-GARCH 모형을 적합시킨 후 $t-1$ 시점부터 $t-22$ 시점까지의 양 수와 음수, 총 44 개의 수익률들을 설명변수로 하여 $\mathrm{LASSO}$ 를 실시한 결과는 다음과 같다.

$$
\begin{aligned}
h_{t}= & 0.373620+0.328910 \epsilon_{t-2}^{+2}+0.237450 \epsilon_{t-3}^{+2}+0.171545 \epsilon_{t-4}^{+2}+0.123048 \epsilon_{t-5}^{+2} \\
& +0.087413 \epsilon_{t-6}^{+2}+0.061967 \epsilon_{t-7}^{+2}+0.043560 \epsilon_{t-8}^{+2}+0.029881 \epsilon_{t-9}^{+2}+0.020729 \epsilon_{t-10}^{+2} \\
& +0.014145 \epsilon_{t-11}^{+2}+0.0085620 \epsilon_{t-12}^{+2}+0.005067 \epsilon_{t-13}^{+2}+0.003073 \epsilon_{t-14}^{+2}+0.001806 \epsilon_{t-15}^{+2} \\
& +0.000023 \epsilon_{t-16}^{+2}+0.008290 \epsilon_{t-1}^{-2}+0.130008 \epsilon_{t-2}^{-2}+0.093662 \epsilon_{t-3}^{-2}+0.067584 \epsilon_{t-4}^{-2} \\
& +0.052437 \epsilon_{t-5}^{-2}+0.039254 \epsilon_{t-6}^{-2}+0.031619 \epsilon_{t-7}^{-2}+0.024563 \epsilon_{t-8}^{-2}+0.016460 \epsilon_{t-9}^{-2} \\
& +0.012314 \epsilon_{t-10}^{-2}+0.009642 \epsilon_{t-11}^{-2}+0.006773 \epsilon_{t-12}^{-2}+0.002620 \epsilon_{t-13}^{-2} .
\end{aligned}
$$

분석결과 총 44 개의 수익률 중 28 개의 수익률만이 $t$ 시점의 변동성에 영향을 주고 있음을 알 수 있다. 또 한 계수들을 보면 양수 부분 수익률과 음수 부분 수익률 각각에 대하여 모두 $t-2$ 시점에서의 수익률이 가장 영향력이 큰 것을 알 수 있다.

가장 영향력이 큰 $t-2$ 시점의 양의 수익률, 음의 수익률과 변동성의 LASSO NIC는 다음과 같다.

$$
h_{t}=0.328910 \epsilon_{t-2}^{+2}+0.130008 \epsilon_{t-2}^{-2}+1.476103 \text {. }
$$

추정식에서 $\epsilon_{t-2}^{+2}$ 에 의한 변동성이 $\epsilon_{t-2}^{-2}$ 에 의한 변동성보다 3 배 더 큰 것을 알 수 있다. 이는 나쁜 정보 가 좋은 정보보다 변동성에 더 크게 영향을 준다는 기존의 비대칭 효과(leverage effect)와 반대되는 경 향임을 알 수 있다. 이는 LASSO NIC를 그린 Figure 4.2(a)를 통해서도 확인할 수 있다. 비대칭성을 보이고 있으며, 음의 부분의 기울기보다 양의 부분의 기울기가 더 가파름을 보여주고 있다. 기존의 비대 칭 효과와 반대되는 방향을 얻은 이유는 $\mathrm{KOSDAQ}$ 자료의 경우 같은 양일 때 음의 수익률 보다는 양의 수익률에 더 큰 위험을 느끼는 것으로 해석 할 수 있다. 이러한 반대 방향의 비대칭 효과는 원화강세 기 간 중에 일별 대미환율(1달러당 원화)자료에서도 종종 나타난다. 


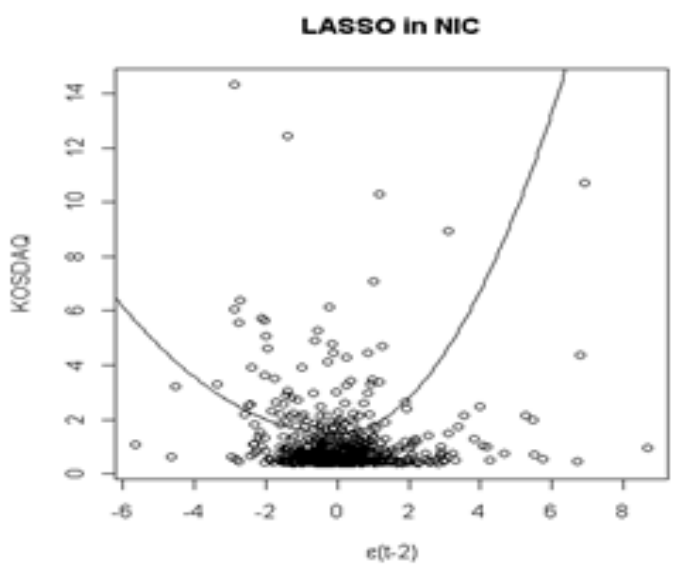

(a) LASSO NIC

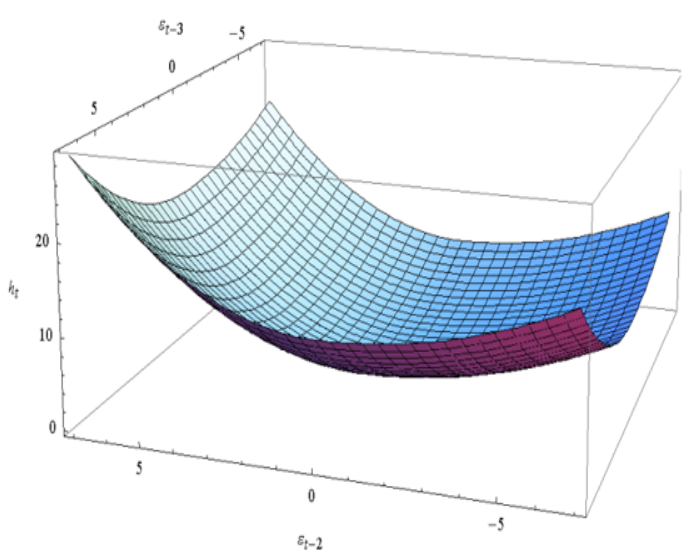

(b) LASSO 2 차원 NIC

Figure 4.2. T-GARCH $(1,1)$

$\mathrm{LASSO}$ 분석을 실시한 결과를 보면 양수 수익률과 음수 수익률 부분에서 공통적으로 $t-2$ 시점에서 의 수익률 다음으로 $t-3$ 시점에서의 수익률의 영향력이 큼을 알 수 있다. 이를 반영하여 $t-2$ 시점과 $t-3$ 시점에서의 수익률을 이용하여 추정한 LASSO 2 차원 $\mathrm{NIC}$ 는 다음과 같다.

$$
h_{t}= \begin{cases}0.328910 \epsilon_{t-2}^{+2}+0.237450 \epsilon_{t-3}^{+2}+1.165017, & \text { if } \epsilon_{t-2}>0 \text { and } \epsilon_{t-3}>0, \\ 0.328910 \epsilon_{t-2}^{+2}+0.093662 \epsilon_{t-3}^{-2}+1.165017, & \text { if } \epsilon_{t-2}>0 \text { and } \epsilon_{t-3}<0, \\ 0.130008 \epsilon_{t-2}^{-2}+0.237450 \epsilon_{t-3}^{+2}+1.165017, & \text { if } \epsilon_{t-2}<0 \text { and } \epsilon_{t-3}>0, \\ 0.130008 \epsilon_{t-2}^{-2}+0.093662 \epsilon_{t-3}^{-2}+1.165017, & \text { if } \epsilon_{t-2}<0 \text { and } \epsilon_{t-3}<0 .\end{cases}
$$

Figure 4.2(b)는 위 식을 그래프로 그린 것이다. LASSO NIC와 동일하게 LASSO 2 차원 NIC에서도 $\mathrm{T}-\mathrm{GARCH}(1,1)$ 모형의 특징인 비대칭성을 보이고 있으며, $\left(\epsilon_{t-2}, \epsilon_{t-3}\right)=(0,0)$ 에서 $t$ 시점 변동성의 최 솟값을 가지고 모든 방향으로 비대칭적으로 증가하고 있음을 알 수 있다. 또한 $t-2$ 시점의 수익률과 $t-3$ 시점의 수익률 모두 양의 방향으로 증가할 때 $t$ 시점의 변동성에 가장 크게 영향을 준다는 것을 알 수 있다.

\section{3. 모형 3: $\mathrm{BL}-\mathrm{GARCH}(1,1)$ - LASSO NIC와 LASSO 2차원 NIC}

749 개의 $\mathrm{KOSDAQ}$ 수익률 데이터에 BL-GARCH 모형을 적합시킨 후 $t-1$ 시점부터 $t-22$ 시점까지의 수익률들과 수익률의 제곱 총 44 개의 수익률들을 설명변수로 $\mathrm{LASSO}$ 를 실시한 결과는 다음과 같다.

$$
\begin{aligned}
h_{t}= & 0.291594+0.013930 \epsilon_{t-1}^{2}+0.164860 \epsilon_{t-2}^{2}+0.107650 \epsilon_{t-3}^{2}+0.060876 \epsilon_{t-4}^{2}+0.031583 \epsilon_{t-5}^{2} \\
& +0.019427 \epsilon_{t-6}^{2}+0.012787 \epsilon_{t-7}^{2}+0.017800 \epsilon_{t-8}^{2}+0.004491 \epsilon_{t-9}^{2}+0.003871 \epsilon_{t-10}^{2} \\
& +0.001226 \epsilon_{t-11}^{2}+0.002909 \epsilon_{t-12}^{2}+0.003834 \epsilon_{t-13}^{2}+0.003242 \epsilon_{t-14}^{2}+0.002310 \epsilon_{t-17}^{2} \\
& -0.002812 \epsilon_{t-20}^{2}+0.002887 \epsilon_{t-21}^{2}-0.002116 \epsilon_{t-22}^{2}-0.056248 \epsilon_{t-1}+0.267598 \epsilon_{t-2} \\
& +0.158520 \epsilon_{t-3}+0.103401 \epsilon_{t-4}+0.074695 \epsilon_{t-5}+0.059457 \epsilon_{t-6}+0.04418 \epsilon_{t-7}+0.003764 \epsilon_{t-9} \\
& +0.006454 \epsilon_{t-10}+0.003892 \epsilon_{t-16}-0.000296 \epsilon_{t-19}+0.008084 \epsilon_{t-22}
\end{aligned}
$$




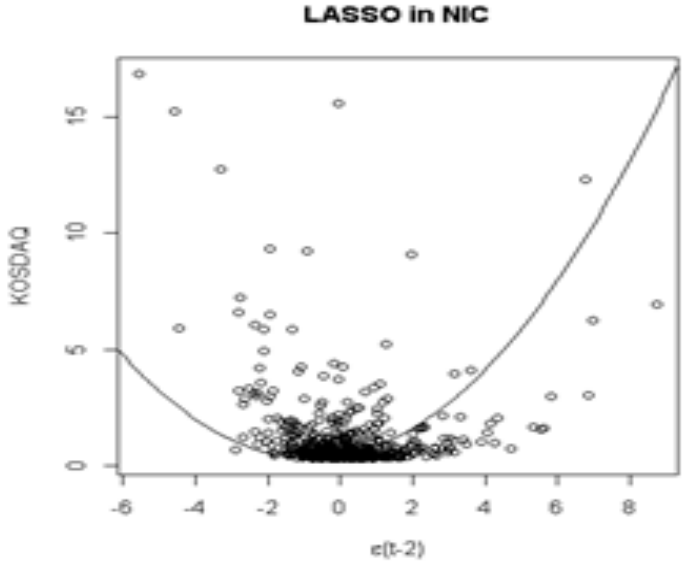

(a) LASSO NIC

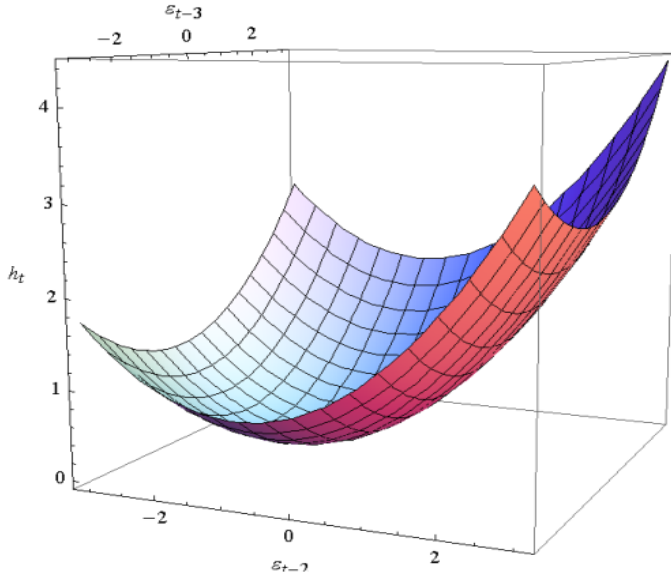

(b) LASSO 2차원 NIC

Figure 4.3. BL-GARCH $(1,1)$

결과를 보면 총 44 개의 수익률 중 30 개의 수익률이 $t$ 시점에서의 변동성에 영향을 주고 있음을 알 수 있 다. 그 중 가장 영향력이 있는 변수는 $t-2$ 시점에서의 수익률이며 이 수익률과 변동성과의 관계를 나타 낸 LASSO NIC는 다음과 같다.

$$
h_{t}=0.164860 \epsilon_{t-2}^{2}+0.267598 \epsilon_{t-2}+0.434333 .
$$

이를 그래프로 나타내면 Figure 4.3(a)와 같으며, 0 을 중심으로 비대칭인 것을 확인할 수 있다.

$t-2$ 시점에서의 수익률 다음으로 $t-3$ 시점에서의 수익률의 영향력이 큼을 알 수 있는데 이를 고려하 여 $t-3$ 시점에서의 수익률까지 사용한 LASSO 2 차원 NIC는 다음과 같으며 그래프로 나타내면 Figure $4.3(\mathrm{~b})$ 와 같다.

$$
h_{t}=0.164860 \epsilon_{t-2}^{2}+0.267598 \epsilon_{t-2}+0.107650 \epsilon_{t-3}^{2}+0.158520 \epsilon_{t-3}+0.379085 .
$$

LASSO 2차원 NIC를 통해 LASSO NIC와 동일하게 비대칭성을 보이고 있음을 알 수 있다.

\section{5. 결론}

기존의 $\mathrm{NIC}$ 를 확장한 2 차원 $\mathrm{NIC}$ 와 주성분 $\mathrm{NIC}$ 를 확장하여 한 달간의 수익률이 변동성에 미치는 영향 을 고려하기 위해 한 달 동안의 수익률을 변동성을 설명하는데 있어 필수적인 수익률들로 차원을 축소하 여 이를 이용한 LASSO NIC를 제안하였다. 또한 LASSO NIC에서 영향력이 두 번째로 큰 수익률 변수 를 추가한 LASSO 2차원 NIC를 제안하였다. 일부 두 시점 혹은 다섯 시점의 수익률만을 고려했던 것 에서 과거 한 달 동안의 수익률과 변동성과의 관계가 어떻게 나타나는지 그래프를 통해 나타내었다는 점 에서 유용하다고 생각된다. 또한 LASSO NIC는 수익률 자체를 직접 반영하므로 인공변수를 이용하는 주성분 $\mathrm{NIC}$ 보다 해석이 용이하다는 장점이 있다.

\section{References}

Bollerslev, T. (1986). Generalized autoregressive conditional heteroscedasticity, Journal of Econometrics, 31, 307-327. 
Choi, M. S., Park, J. A. and Hwang, S. Y. (2012). Asymmetric GARCH processes featuring both threshold effect and bilinear structure, Statistics \& Probability Letters, 82, 419-426.

Engle, R. F. (1982). Autoregressive conditional heteroskedasticity with estimates of the variance of United Kingdom inflation, Econometrica, 50, 987-1008.

Engle, R. F. and Ng, V. K. (1993). Measuring and testing the impact of news on volatility, Journal of Finance, 48, 1749-1778.

Lee, J. W., Yoon, J. E. and Hwang, S. Y. (2013). A graphical improvement in volatility analysis for financial series, Korean Journal of Applied Statistics, 26, 785-796.

Park, C., Kim, Y., Kim, J., Song, J. and Choi, H. (2011). Data Mining using R, Kyowoosa, Seoul.

Rabemananjara, R. and Zakoian, J. M. (1993). Threshold ARCH models and asymmetries in volatility, Journal of Applied Econometrics, 8, 31-49.

Storti, G. and Vitale, C. (2003). BL-GARCH models and asymmetries in volatility, Statistical Methods and Applications, 12, 19-40.

Tibshirani, R. (1996a). Regression shrinkage and selection via the lasso, Journal of the Royal Statistical Society, 58, 267-288.

Tibshirani, R. (1996b). Regression shrinkage and selection via the lasso: A retrospective, Journal of the Royal Statistical Society, 73, 273-282. 


\title{
LASSO를 이용한 비대칭 GARCH 모형의 변동성 커브
}

\author{
윤재은 $^{a} \cdot$ 이정원 ${ }^{a} \cdot$ 황선영 $a, 1$ \\ ${ }^{a}$ 숙명여자대학교 통계학과
}

(2014년 1월 22일 접수, 2014년 2월 4일 수정, 2014년 2월 6일 채택)

요 약

Engle과 Ng (1993)가 제안한 뉴스 임팩트 커브(NIC)는 표준적인 GARCH 모형에 적용되는 대칭 커브이다. 최근 들어 금융시계열의 변동성이 비대칭 성질을 가지는 경향이 있으며 이에 따라 분계점(threshlod) GARCH, 이중선 형(bilinear) GARCH 등의 비대칭 모형이 연구되고 있다. 본 논문은 비대칭 모형의 변동성 커브에 대해 연구하고 있으며 LASSO를 통한 방법론을 제안하고 있다. 제시된 방법론을 국내 KOSDAQ 자료분석을 통해 예시해 보았다.

주요용어: 이중선형-GARCH, Lasso, 이차원 뉴스 임팩트 커브.

${ }^{1}$ 교신저자: (140-742) 서울특별시 용산구 청파로47길 100 , 숙명여자대학교 통계학과, 교수.

E-mail: shwang@sookmyung.ac.kr 